\title{
Cultura organizacional para el cuidado del medioambiente estudio de caso sector floricultor en Cota-Cundinamarca
}

\section{Organizational culture for the care of the environment: case study of the floriculture sector in Cota-Cundinamarca}

\author{
Esperanza Diaz Vargas ${ }^{1}$ https://orcid.org/0000-0002-1410-4279, \\ Gerardo Mogollón Pita ${ }^{1}$ https://orcid.org/0000-0002-6412-6740 \\ ${ }^{1}$ Facultad de Economía, Empresa y Desarrollo Sostenible. FEEDS, Universidad de \\ La Salle, Bogotá, Colombia \\ esperanzadiazveunisalle.edu.co, gmogollon@unisalle.edu.co
}

Esta obra está bajo una licencia internacional

Creative Commons Atribución-NoComercial 4.0.

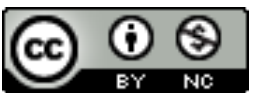

$\begin{array}{ll}\text { Enviado: } & 2021 / 11 / 09 \\ \text { Aceptado: } & 2021 / 12 / 29 \\ \text { Publicado: } & 2021 / 12 / 30\end{array}$

\section{Resumen}

El cultivo de flores es una actividad multicultural y requiere de un trabajo colectivo que permita la inclusión y la comunicación entre sus líderes y colaboradores. Las necesidades de cambio en el sector son relevantes y el fin es evitar las malas prácticas que afectan al personal y al medio ambiente. A ello se suman las dificultades para exportar y disminuir la tensión laboral y la baja eficiencia. Otro inconveniente es la falta de una cultura organizacional fuerte que permita alinear el plan estratégico empresarial con el adecuado desempeño de sus trabajadores que ocasiona una falta de participación consciente de los líderes para contrarrestar el daño ambiental y el inadecuado clima laboral. Este documento caracteriza la estrategia de gestión humana y el impacto que genera en la cultura organizacional y la afectación sobre el medio ambiente de las empresas del sector floricultor de La Sabana de Bogotá. Como resultados del estudio cuenta el Impacto social: Potenciar capacidades de negociación en las organizaciones del sector floricultor para que gerencien su actividad en contextos plurales, diversos y amigables con el medioambiente. Lo expuesto, deriva en mayor productividad, la calidad de vida laboral y bienestar ambiental. Sobre el Impacto de trasferencia: El estudio cuenta con herramientas teórico-prácticas y técnicas que permiten optimizar la relación del capital humano y el proceso productivo con los impactos negativos que este genera sobre el medioambiente, brindando ventajas competitivas en gestión administrativa, calificación del recurso humano, sistema de gestión ambiental, acceso a nuevos mercados y financiamiento, entre otras, gestionando organizaciones agroindustriales sostenibles.

Sumario: Introducción, Metodología, Discusión de resultados y Conclusiones.

Como citar: Diaz, E. \& Mogollón, G. (2021). Cultura organizacional para el cuidado del medioambiente estudio de caso sector floricultor en Cota-Cundinamarca. Revista Tecnológica - Espol, 33(3), 85-109.

http://www.rte.espol.edu.ec/index.php/tecnologica/article/view/880 
Palabras clave: Cultura organizacional, medioambiente, sector floricultor.

\begin{abstract}
Floriculture is a multicultural activity. It requires collective work that allows inclusion and communication between leaders and collaborators. The needs for change in the sector are relevant and the aim is to avoid bad practices that affect personnel and the environment. In addition, there are difficulties in exporting and reducing labor tension and low efficiency. Another drawback is the lack of a strong organizational culture to align the company's strategic plan with the adequate performance of its workers, which leads to a lack of conscious leaders' participation to counteract environmental damage and an inadequate working environment. This document characterizes the human management strategy and the impact it generates on the organizational culture and the effect of the companies in the floriculture sector of La Sabana de Bogotá on the environment. The results of the study include the social impact with the strengthening of negotiation skills in the organizations of this floriculture sector so that they can manage their activity in plural, diverse, and environmentally friendly contexts. This results in higher productivity, quality of working life, and environmental wellbeing. Regarding the transfer impact, this case study has theoretical-practical and technical tools that allow optimizing the relationship between human capital and the production process with their negative impacts on the environment. This provides competitive advantages in administrative management, human resources qualification, environmental management system, access to new markets, and financing, allowing the management of sustainable agro-industrial organizations.
\end{abstract}

Keywords: Organizational culture, environment, and floriculture sector.

\title{
Introducción
}

En el informe de gestión del año 2020 de la Superintendencia de sociedades, menciona que una de las estrategias para mantener empresas competitivas, productivas y perdurables, es "el uso eficiente de recursos mediante una gestión eficaz que genera mejores y oportunas respuestas al mercado y al entorno" (Superintendencia de sociedades, 2020, p. 45). En ese sentido, uno de los pilares de la política de supervisión de la SuperSociedades ${ }^{1}$ se encuentra en la educación o actividad pedagógica para poder propagar en el empresariado colombiano una cultura de cumplimiento normativo.

De hecho, se establecen múltiples recursos pedagógicos como guías, vídeos informativos, aulas virtuales, jornadas de socialización en eventos presenciales o virtuales, entre otros, que han permitido masificar la información y hacer pedagogía de estos componentes tan relevantes para el sector empresarial. Todo, en palabras de la SuperSociedades, a partir del correo electrónico con terminal o domino @ pedagogiaempresarial.gov.co. Estrategia que ha sido acompañada por otros estamentos de la nación como la Cámara de Comercio de Bogotá y Confecámaras, en la cual se destaca el documento Guía de Buenas Prácticas de Gobierno Corporativo para empresas competitivas, productivas y perdurables.

Según Informe de la Superintendencia de sociedades (2017). "El sector floricultor se caracteriza por su impacto en la generación de 130.000 empleos formales (directos e indirectos)" (Superintendencia de sociedades, 2017, p. 17). Con relación a esto, se puede

\footnotetext{
${ }^{1}$ Superintendencia de Sociedades. De ahora en adelante se hará esta denominación: SuperSociedades.
} 
mencionar también que La Sabana de Bogotá se convierte en el centro de ubicación del sector floricultor de Colombia, el cual desde hace varias décadas constituye uno de los sectores de la economía colombiana con importante presencia en el mercado internacional.

De acuerdo con el reporte presentado por el DANE, el 14\% de la producción mundial en el año 2004 y con un peso cercano al 3\% de las exportaciones colombianas [...] En la actualidad el sector Floricultor cuenta con 7.290 has, cultivadas y dedicadas al corte de flores frescas para la exportación. En 2006 el área cultivada era 7000 has. El 79\% del área cultivada se encuentra ubicada en La Sabana de Bogotá, 17\% en Antioquia y 4\% en otros departamentos, entre los que se incluyen Valle del Cauca y Eje Cafetero. (Departamento Administrativo Nacional de Estadística, 2010, p. 8)

Con relación a lo anterior, es posible considerar que, si bien los estudios en empresas floricultoras muestran gran interés por la dinámica de poder, así como su amplio crecimiento económico y de producción que claramente afectan el clima laboral y por ende la productividad de la organización, se requiere dar una mirada al compromiso medioambiental de todos los actores implicados, y más aún, en cambios tan significativos en el medioambiente.

En ese sentido, se hace necesario comprender los acontecimientos que ocurren dentro de la organización. A su vez, es imprescindible estar atentos a todas las dinámicas relacionadas con la articulación entre el medioambiente, el sistema organizacional y su entorno. Dado que es necesario comprenderlo como un solo ecosistema y, si no se conjugan en procesos de una cultura organizacional que valore e imparta normas para conservar el equilibrio a través de sus líderes, se verá seriamente afectada la empresa. Por tal razón, esta investigación busca acercarse a la construcción de realidad del líder y la de sus colaboradores en la empresa floricultora elegida.

Para dar un direccionamiento a estas pretensiones investigativas, se establece como interrogante de trabajo ¿Cuáles son los efectos de la cultura organizacional en el comportamiento de sus colaboradores y el medioambiente en las empresas del sector floricultor de La Sabana de Bogotá? En ese sentido, para el desarrollo de esta ruta de investigación, se plantea como objetivo analizar los efectos que el proceso productivo de las empresas del sector floricultor de la Sabana de Bogotá causan sobre el medioambiente y la cultura organizacional.

Basados en la precisión anterior, a continuación, se exponen los referentes metodológicos por los cuales se guía esta investigación y que permiten consolidar algunas reflexiones y posteriores conclusiones de acuerdo con los intereses proyectados para este estudio.

\section{Metodología}

La metodología que se utilizó fue el método plataforma con un enfoque cualitativo por ser un estudio de caso en el cual los investigadores se apoyaron en la Investigación Acción Participativa (IAP) entendiéndola como un recurso fundamental para la comprensión de todas las dinámicas que circulan en este contexto empresarial y bajo los intereses de la investigación alrededor de la articulación entre la organización y su impacto en el medioambiente. Para lo anterior, es necesario mencionar que el enfoque fue inductivo, ya que se tomó el caso particular de las empresas del sector floricultor de La Sabana de Bogotá, para que a la luz de la teoría existente se propicie un mejoramiento continuo al interior de cada organización.

El propósito fue evaluar los efectos que, sobre la eficiencia de la organización, tenga un adecuado clima laboral y una correcta aplicación de la normatividad ambiental, en una 
cultura organizacional fortalecida por las buenas prácticas empresariales encaminadas por líderes comprometidos con lo que hacen.

Por lo anterior, la información obtenida se analizó en torno al método ideal para las ciencias sociales, es decir, el Crítico - hermenéutico que consistió en establecer un sistema de comunicación abierto, horizontal y dialéctico que facilitó una mirada crítica de los fenómenos que circundan al objeto de estudio.

Se utilizó como instrumentos de medición las encuestas digitales aplicadas a una población de 100 trabajadores del sector floricultor de La Sabana de Bogotá. Según la encuesta los datos serían:

\section{Tabla 1}

Encuestas digitales aplicadas a una población de 100 trabajadores del sector floricultor de la Sabana de Bogotá

\begin{tabular}{|l|c|c|}
\hline \multicolumn{1}{|c|}{ Cargo } & No. personas & Porcentaje \\
\hline Directores(a) & 6 & $6 \%$ \\
\hline Jefaturas & 6 & $6 \%$ \\
\hline Supervisores(a) & 23 & $23 \%$ \\
\hline Operarios(a) & 52 & $52 \%$ \\
\hline Asistentes y/o Auxiliares & 13 & $13 \%$ \\
\hline Total & 100 & $100 \%$ \\
\hline
\end{tabular}

Fuente: Elaboración propia

De acuerdo con los datos presentados en la tabla anterior, es relevante mencionar que se trabajó de manera selectiva las 25 preguntas del Instrumento de Diagnóstico de Cultura Organizacional (IDCO), con relación a: Objetivos, Cooperación, Liderazgo, Toma de decisiones y Relaciones Interpersonales.

A partir de los datos obtenidos, es posible considerar que la mayoría de los colaboradores de la muestra seleccionada, hacen parte del sector operario de este tipo de organización. En ese sentido, se expone la importancia de este sector poblacional y su relación intrínseca con las dinámicas medioambientales y de cuidado que deben ser consideradas en una empresa. A su vez, en la consolidación de un clima laboral propicio para el cumplimiento de todas las normativas entorno a los impactos medioambientales que ejercen este tipo de compañía, pues, al mitigar el impacto o la insatisfacción laboral en este tipo de cargos, mejora la productividad, la relación con la empresa y, por tanto, con el entorno al que se impacta.

\section{Discusión de Resultados}

\section{La cultura organizacional y sus efectos en los floricultores de La Sabana de Bogotá}

En un mundo donde los cambios son rápidos y las personas requieren adaptarse de forma casi inmediata, de lidiar con la incertidumbre, de mantenerse en sus trabajos con una actitud positiva y comprometida, se hace necesario contar con líderes que permitan aportar ideas y acciones concretas que faciliten escenarios laborales cómodos. Además, de horarios más versátiles para lograr que el personal se comprometa y sea eficiente en una cultura organizacional autentica y fortalecida por ideales comunes en pro de un bienestar colectivo. 
De acuerdo con lo que propone Eichholz (2015), las organizaciones innovadoras por lo general cuentan con personas que tienden a aceptar los desafíos, pues su trabajo es de naturaleza más adaptativa, compleja y orientada hacia el talento, mientras que los empleados de una organización resolutiva lo hacen más bien como una respuesta de una presión exterior. (p. 229)

De allí lo importante de establecer una cultura organizacional que permita enfrentar los problemas con personas que tengan interiorizado su compromiso y logren establecer una comunicación efectiva con sus jefes o líderes de área. Si bien la cultura es el ADN de toda organización, también es producto del esquema mental de sus líderes, quienes no solo llevan conocimiento a sus lugares de trabajo sino sus creencias, ideas, valores y sentimientos. Todo lo expuesto se traduce en comportamientos que los trabajadores interpretan como buenos o no.

Las estrategias de gestión humana en las empresas del sector floricultor por lo general están centradas en trabajar a favor de los colaboradores realizando mejores procesos de selección, evaluación, capacitación, salud y seguridad laboral y así garantizar la fuerza profesional idónea para realizar las tareas. Esta acción permite dar respuesta a la exigencia de sus clientes internos y externos, procurando sancionar el error, donde el trabajador por miedo, oculta su falla y agudiza lo que fue una falta de comunicación y confianza hacia su jefe en problemas que se reflejan en el proceso productivo de la organización, ocasionando altos niveles de rotación y dificultades de clima laboral.

Entendiendo el recurso humano como un eje fundamental en la gestión empresarial, a través de los años las empresas y los empleadores han buscado comprender las costumbres e imaginarios propios de los trabajadores tales como sus principales motivaciones, propósitos, aspiraciones económicas y sociales y en general la forma de comprender el mundo laboral. Estas particularidades, entendidas como esos rasgos característicos de un grupo de trabajo a través de los que se define un comportamiento y forma de percibir el entorno, integran la cultura organizacional de una empresa.

Además de lo anterior, la cultura exógena(externa) permea la cultura endógena(interna) de la empresa y es más evidente en época de pandemia donde aún se vive en permanente zozobra por el temor a contagiarse o contagiar a sus familiares o compañeros de trabajo. En medio de tanta incertidumbre, los empresarios, gremios y entes gubernamentales generaron estrategias de prevención y cuidado hacia sus empleados, procurando alinearlas para seguir respondiendo ante los compromisos adquiridos a sus clientes.

En marzo 2020, una de las empresas más afectadas fue sector floricultor colombiano, ya que la producción de flores estaba para ser entregada en fechas especiales como día de San Valentín (14 de febrero), Día de la Mujer (8 de marzo), Día de la Madre (10 de mayo), etc. Las restricciones eran cada vez más rigurosas y los medios de transporte tanto terrestre como aéreo eran prohibidos.

Como se puede ver en la Figura 1, el impacto de la cultura exógena en la endógena es evidente y genera un proceso de adaptación inmediato a nuevas maneras de comportamiento y con un grado de responsabilidad mayor por el uso de todos los mecanismos de protección que exigía la pandemia. Otro de los factores que determinó cambios en el comportamiento de los floricultores fue la orden de que los niños y jóvenes no fueran a estudiar. Según (Ávila 2018) la jornada escolar colombiana es comparativamente corta debido a que el gobierno le ha dado prioridad a la cobertura. Ello trae consigo dificultades para la crianza y la formación de los 
hijos de personas que deben de permanecer en la empresa una buena parte del día, sin estar seguras de lo que hacen los hijos durante el tiempo libre.

\section{Figura 1}

\section{Relación Exógena-Relación Endógena}

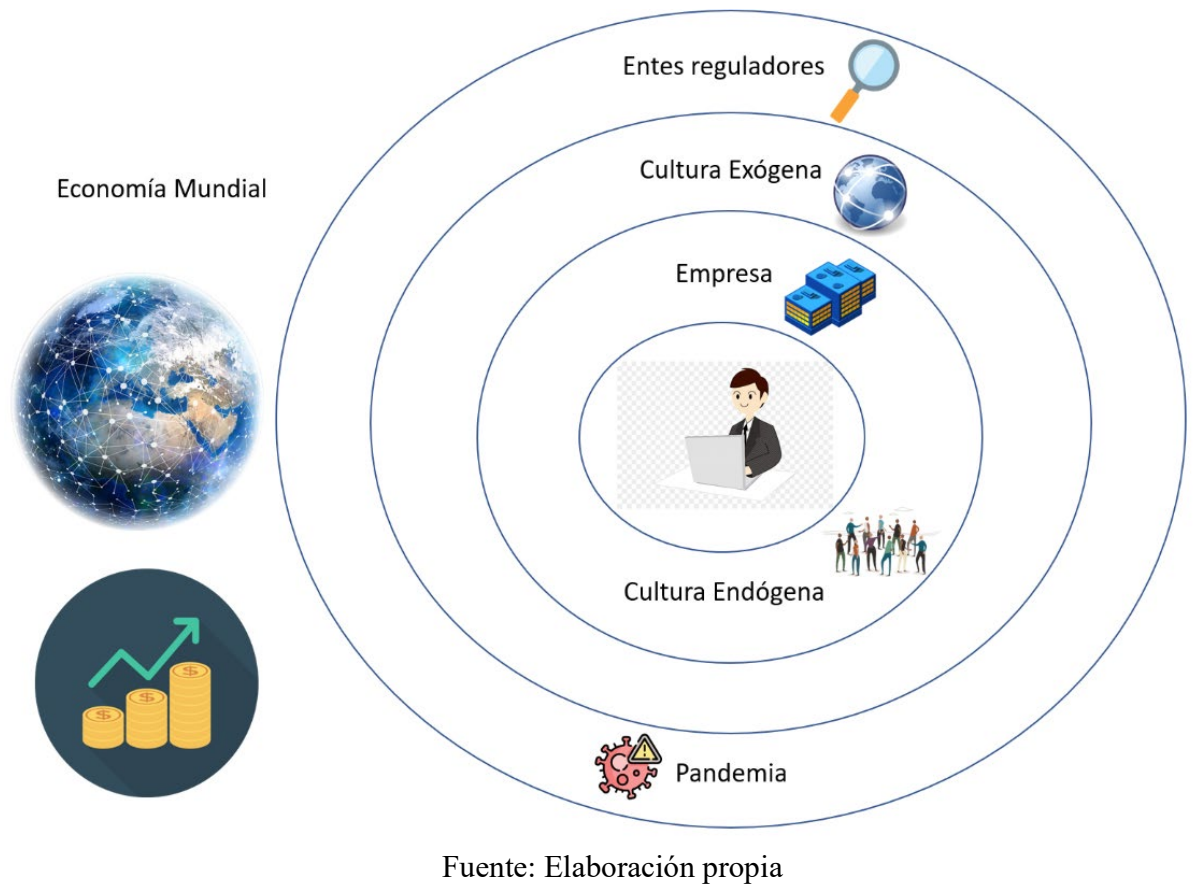

Por tal razón, los empleadores se esmeran por entender y comprender los pormenores que definen la cultura organizacional de su empresa; velando porque esta cultura no se contamine con aspectos negativos que afecten su entorno. Por el contrario, los verdaderos líderes se encargan de blindar su organización y buscar los mecanismos para que su cultura se fortalezca, permitiendo así superar las dificultades y hacer frente a los desafíos sociales y empresariales de estos tiempos. (Ortiz y Rodríguez. 2018, pág. 4)

El sector floricultor se destaca como un generador de desarrollo en Colombia, pues es intensivo en el uso de la mano de obra si se compara con otros sectores del agro, por cada hectárea se generan 17,3 empleos (Méndez, 2006). Según estudios de Asocolflores (2017), la población que mayormente trabaja en el sector son mujeres, proceden de las áreas en las que se encuentran los cultivos de flores, han sufrido desplazamiento y en gran medida son madres cabezas de familia con al menos una formación mínima.

\section{Características de la empresa caso estudio Cota-Cundinamarca Sabana de Bogotá}

En el caso de la empresa de flores en cota de la Sabana de Bogotá, se puede apreciar, a partir de los datos recolectados en el proceso investigativo, que el $74.74 \%$ de las personas que laboran allí son mujeres, el $24.21 \%$ son hombres y el $1.05 \%$ tiene otro género. Esto hace ser más flexibles e incluyentes en los procesos de selección, donde este trabajo tiende a caracterizarse por la mano de obra femenina. En la escolaridad se encuentra de forma significativa que el $41.05 \%$ de los trabajadores evaluados tienen un nivel educativo de secundaria, el $30.53 \%$ de primaria, el $11.58 \%$ nivel técnico o tecnólogo y el $14.74 \%$ universitario y un $2.11 \%$ en posgrado. 
Esta empresa permite generar procesos de aprendizaje organizacional ya que cuenta con una población que, en su mayoría, pueden disponer de conocimiento básico, medio y superior para seguir profesionalizando la organización, mejorando su actividad y productividad, siempre que los lideres permitan un trabajo más participativo en la resolución de problemas y toma de decisiones dentro de los equipos que direccionan. También se identifica que el $36.84 \%$ de los colaboradores son mayores de 50 años; otro de los grupos significativos es el que se encuentra entre los 40 y 50 años con un $29.47 \%$, entre los 30 y 40 años, el $23.16 \%$. Y de los 20 a 30 años, el $9.47 \%$ y solo un $1.05 \%$ de los colaboradores son menores de 20 años.

Por lo que se puede deducir que el $66.31 \%$ de colaboradores son mayores de 40 años, personas que posiblemente están por jubilarse, pensando que sean mujeres, de acuerdo con la estadística antes mencionada, sería muy importante conocer si la empresa tiene un plan de sucesión para los cargos donde se encuentran la gran mayoría de estas trabajadoras. Por otro lado, destacar el grado de perdurabilidad del que gozan en la empresa, lo cual es atribuido al cumplimiento de sus obligaciones contractuales como empleador, una nómina que esta al día, con prestaciones sociales y apoyos para el colaborador, destacándose el buen manejo de bienestar laboral y del área de seguridad y salud ocupacional, como el tipo del contrato laboral, que en su mayoría es a término indefinido.

\section{Figura 2}

Permanencia de los Trabajadores en la Empresa

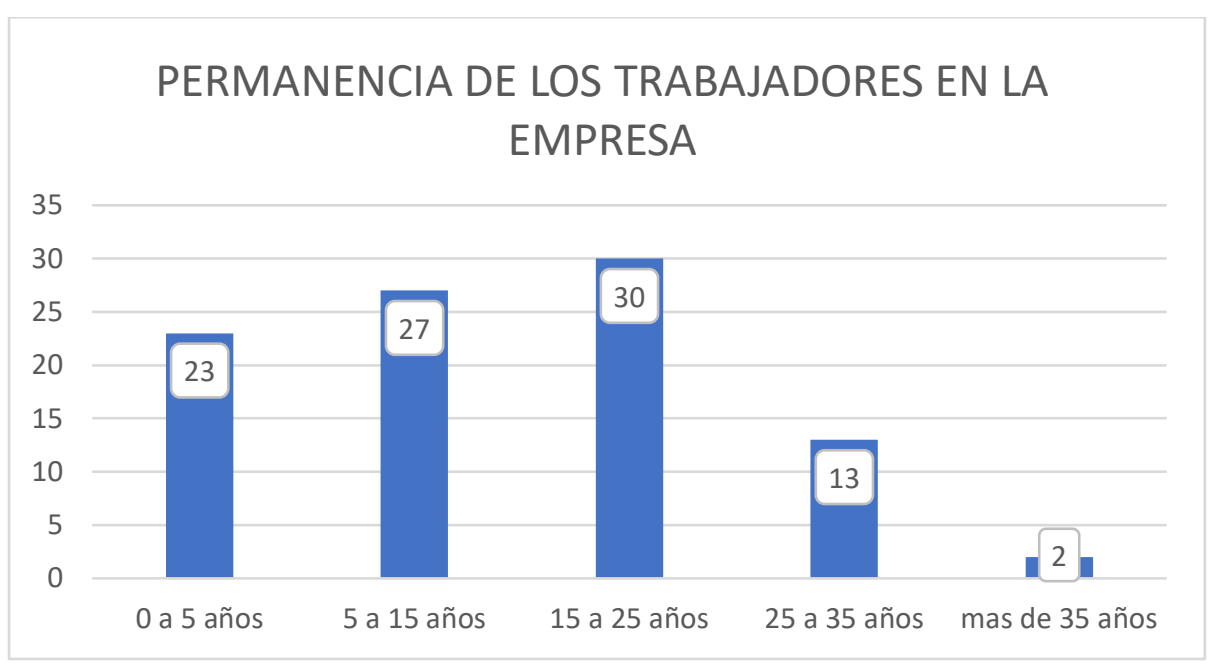

Tabla 2

Permanencia de los trabajadores en la empresa

\begin{tabular}{|l|c|}
\hline \multicolumn{1}{|c|}{ PERMANENCIA } & COLABORADORES \\
\hline 0 a 5 años & 23 \\
\hline 5 a 15 años & 27 \\
\hline 15 a 25 años & 30 \\
\hline 25 a 35 años & 13 \\
\hline más de 35 años & 2 \\
\hline Total & 95 \\
\hline
\end{tabular}

Fuente: Impacto de la estrategia en gestión humana sobre la cultura organizacional y la afectación sobre el medioambiente en las empresas del sector floricultor de La Sabana de Bogotá 
Además, es una empresa que se caracteriza por el alto nivel de permanencia de sus trabajadores. De las 95 personas encuestadas se aprecia que solo 23 de ellos llevan menos de 5 años, mostrando una estabilidad laboral, que concuerda con el buen manejo de su vínculo contractual. Sin embargo, se sugiere a la empresa relacionar la edad con la permanencia y el nivel educativo, de tal manera que se pueda verificar, si las personas con mayor permanencia y edad son las de básica primaria y tal vez este factor educativo sea la causa de no haber cambiado de trabajo y asumir que debían permanecer en esta empresa.

Se sugiere también establecer en las personas jóvenes de la empresa un plan de carrera y apoyarlos académicamente, ya que esto permite mejorar la comunicación en la organización y crear una apertura al cambio de paradigma en el manejo del poder, una de las características más significativas de su actual cultura organizacional.

Después de conocer generalidades de la empresa tomada como caso de estudio, esta investigación evalúa los efectos que, sobre la eficiencia de la organización, tiene un adecuado clima laboral y una correcta aplicación de la normatividad ambiental, en una cultura organizacional fortalecida por las buenas prácticas empresariales encaminadas por líderes comprometidos con lo que hacen y felices de hacerlo. Para ello se realizaron preguntas que se concentraron en algunas de las características de la cultura organizacional: Objetivos, Cooperación, Liderazgo, Toma de decisiones y Relaciones Interpersonales con el Instrumento de Diagnostico de Cultura Organizacional (IDCO).

En cuanto a los Objetivos se les pregunto:

\section{Figura 3}

¿Cómo califica usted los conocimientos que tiene acerca de los objetivos y políticas de la empresa?

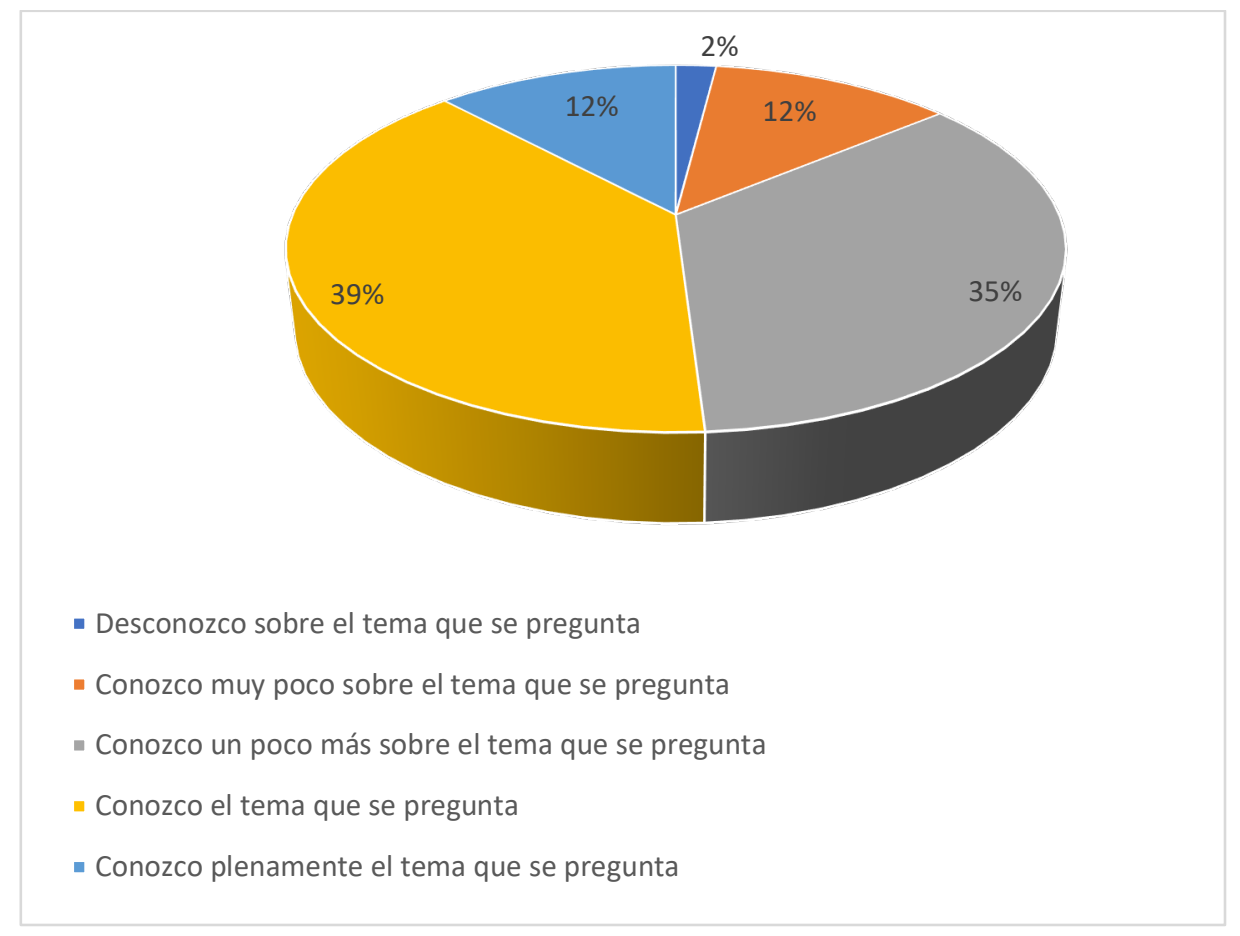




\section{Tabla 3}

¿Cómo califica usted los conocimientos que tiene acerca de los objetivos y políticas de la empresa?

\begin{tabular}{|l|c|c|}
\hline \multicolumn{1}{|c|}{ Selección de pregunta } & Selecciones & \% todas las repuestas de preguntas \\
\hline Desconozco sobre el tema que se pregunta & 2 & $2 \%$ \\
\hline Conozco muy poco sobre el tema que se pregunta & 12 & $12 \%$ \\
\hline Conozco un poco más sobre el tema que se pregunta & 33 & $35 \%$ \\
\hline Conozco el tema que se pregunta & 37 & $39 \%$ \\
\hline Conozco plenamente el tema que se pregunta & 11 & $12 \%$ \\
\hline Total & 95 & $100 \%$ \\
\hline
\end{tabular}

Fuente: Impacto de la estrategia en gestión humana sobre la cultura organizacional y la afectación sobre el medioambiente en las empresas del sector floricultor de la Sabana de Bogotá

Del $95 \%$ de las personas encuestadas, el 38.95\% conocen acerca de los objetivos y políticas de la empresa, el $34.74 \%$ conocen un poco más sobre estos y las políticas, el $12.63 \%$ conocen muy poco sobre el tema que se pregunta y el $11.58 \%$ conocen plenamente el tema que se pregunta, solo el $2.11 \%$ desconocen sobre el tema. La cultura organizacional se hace reconocible y marca los lineamientos del comportamiento de sus trabajadores a través del plan estratégico que los líderes y directivos de la empresa elaboran metódicamente. Buscan dejar la visión y misión que han pensado desde la elaboración de la idea de hombre, trabajo y cliente, que son los lineamientos con los que se marca los valores corporativos de la organización.

Por lo tanto, el que un grupo de personas no consideren que conocen bien los objetivos de la empresa, ni sus políticas pueden generar dificultades en el desempeño de las actividades. Lo que lleva a revisar si hay que ajustar el plan estratégico de gestión humana para alienarlo al plan estratégico de la empresa. La estrategia casi siempre significa cambio organizado. Toda organización necesita tener una pauta de comportamiento holístico en relación con el mundo de los negocios que la circunda y en el cual opera.

La estrategia parte de los objetivos de la misión y de la visión que se pretende realizar y se sustenta en dos tipos de análisis. Por una parte, el análisis del entorno para identificar y analizar las oportunidades que se deben aprovechar y las amenazas que se deben neutralizar o evitar. Se trata de hacer un mapa del entorno para saber qué hay en él.

Por otra parte, el análisis de la organización para detectar e indagar los puntos fuertes y débiles de la empresa. Se trata de una auditoría de las habilidades y las capacidades de la empresa que se deben aplicar plenamente y de los puntos neurálgicos que deben ser corregidos o mejorados. Es una auditoría interna para saber cuál es la vocación de la empresa y no que puede ser más exitosa. Las personas pueden constituir su punto fuerte la principal ventaja competitiva de la empresa o su punto débil la principal desventaja competitiva dependiendo de la manera en que son administradas.

Para obtener sinergia, la estrategia debe ser global y total y no solo un conjunto de acciones aisladas y fragmentadas. Parafraseando a Chiavenato (2009), cuando mayor impacto se genere en el entorno, mayor será la necesidad de establecer estrategias ágiles y flexibles que permitan la consolidación de nuevos caminos y estrategias organizacionales para que la organización esté alineada con las condiciones que requiere la cultura, el medio y la sociedad.

En cuanto a la colaboración se les pregunto: 


\section{Figura 4}

Califique de 1 a 5 (dónde 1 es la calificación más baja y 5 la más alta) ¿La ayuda y colaboración que usted cree que existe entre los trabajadores de esta empresa es?

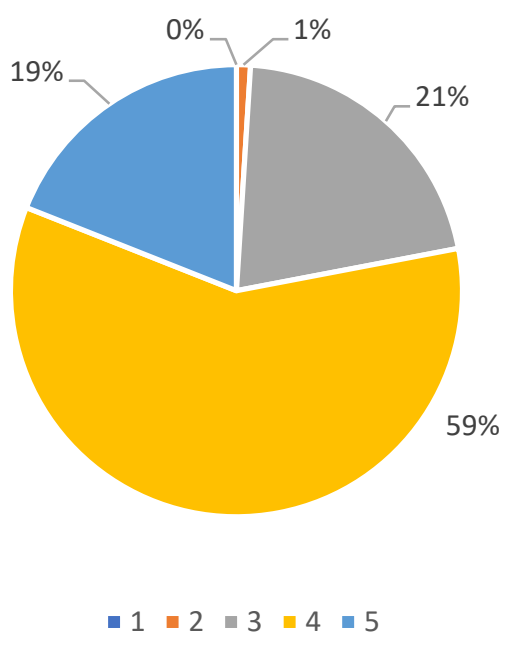

\section{Tabla 4}

Califique de 1 a 5 (dónde 1 es la calificación más baja y 5 la más alta) ¿La ayuda y colaboración que usted cree que existe entre los trabajadores de esta empresa es?

\begin{tabular}{|c|c|c|}
\hline Selección de pregunta & Selecciones & \% todas las repuestas de preguntas \\
\hline 1 & 0 & $0 \%$ \\
\hline 2 & 1 & $1 \%$ \\
\hline 3 & 20 & $21 \%$ \\
\hline 4 & 56 & $59 \%$ \\
\hline 5 & 18 & $19 \%$ \\
\hline Total & 95 & $100 \%$ \\
\hline
\end{tabular}

Fuente: Impacto de la estrategia en gestión humana sobre la cultura organizacional y la afectación sobre el medioambiente en las empresas del sector floricultor de la Sabana de Bogotá

El $58.95 \%$ consideran que la ayuda es alta, el $21.05 \%$ consideran que es normal o adecuada, el $18.95 \%$ consideran que es muy alta y el 1,05\%. Según Stewart, Manz y Sims, (2003) conforme a estos resultados se puede argumentar que la homogeneidad es provechosa en los equipos que deben cooperar y realizar tareas de rutina, como es el caso de la mayoría de población de la empresa estudiada donde el $74.74 \%$ de personas encuestadas pertenece al área operativa (cultivo de la flor). Pero es dañina en los equipos que deben trabajar en tareas que requieren soluciones creativas.

\section{Diversidad cooperación y desempeño}

La diversidad cultural que existe en la empresa es variada, allí confluyen personas de todas partes del país en especial de Regiones como Boyacá, Sucre, Costa Atlántica, Valle del Cauca, Tolima, Antioquia y Cundinamarca. Una de las habilidades más significativas de los directivos en las organizaciones es adaptarse a individuos que son diferentes. El término para describir tal desafío es la fuerza de trabajo diversa.

Mientras la globalización se centra en las diferencias entre individuos procedentes de distintas naciones, la fuerza de trabajo diversa lo hace en las diferencias entre la gente dentro 
de países determinados. El ejercicio de trabajo diverso reconoce una fuerza laboral de mujeres y hombres, muchos grupos raciales y étnicos, personas con una amplia variedad de habilidades físicas y psicológicas e individuos con edades y orientación sexual diferentes.

Para trabajar de manera eficaz con individuos de diferentes culturas, "es necesario que entienda la forma en que fueron moldeados por su cultura, geografía y religión, así como la manera de adaptar su estilo gerencial a sus diferencias”. (Robbins y Judge, 2013, pág. 17)

Para Ávila, María (2018) cuando las personas ven en lo que hacen la realización de sus concepciones se sienten satisfechas y cuando tales actividades hacen parte natural y fluida de la cultura organizacional de la empresa, les resulta más sencilla y estimulante la cooperación con sus pares y con los directivos. Dado que los significados son relativamente compartidos y no es necesario pensar detenidamente si lo que van a decir será entendido o traerá consecuencias negativas, a su vez, los aprendizajes y las mejoras que pudieran surgir en el trabajo resultan pertinentes y emocionantes de forma positiva, dado que se generan en un ambiente abonado por el entendimiento recíproco.

Solo a partir de ese momento, los miembros del grupo sienten como suyo el espacio y los nexos establecidos y se puede asegurar la organización del trabajo en equipos, así como la eficacia del resultado. De allí que los retos van más allá de la administración organizacional, de la racionalización de la estructura (división del trabajo, autoridad, organización, capacitación, fundamento para el control, apertura tecnológica, entre otros). Ese más allá comprende fundamentalmente la calidad de la interacción social, porque en ella se definen los elementos de orden social y cultural que se vinculan con la calidad de las dinámicas sociales de las empresas.

Aquí juega un papel importante la inclusión en el trabajo y la oportunidad de diversificar maneras de pensar la labor que se hace en la empresa, más aún cuando muchos de estos trabajadores provienen de otras finas de flores donde han aprendido otras técnicas para cultivarlas con excelentes resultados. En cuanto a la característica de liderazgo y toma de decisiones en la cultura organizacional se formularon las siguientes preguntas:

\section{Figura 5}

Califique de 1 a 5 (dónde 1 es la calificación más baja y 5 la más alta) la facilidad para plantear a su jefe problemas e inquietudes de su trabajo que usted no puede solucionar

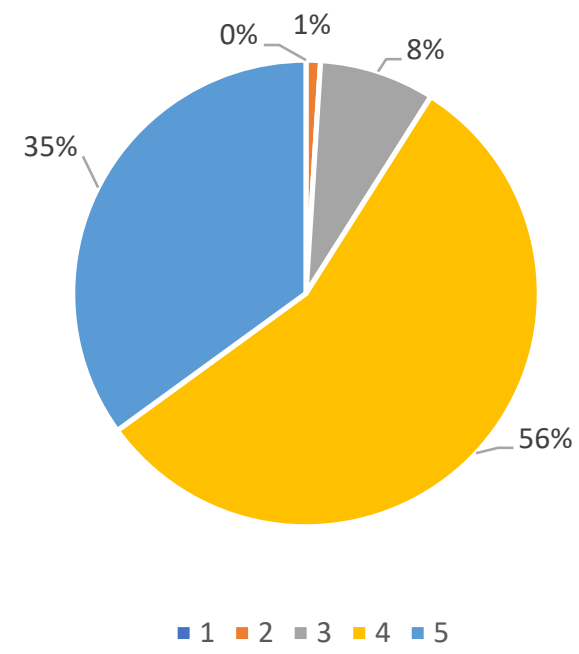




\section{Tabla 5}

Califique de 1 a 5 (dónde 1 es la calificación más baja y 5 la más alta) la facilidad para plantear a su jefe problemas e inquietudes de su trabajo que usted no puede solucionar

\begin{tabular}{|c|c|c|}
\hline Selección de pregunta & Selecciones & \% todas las repuestas de preguntas \\
\hline 1 & 0 & $0 \%$ \\
\hline 2 & 1 & $1 \%$ \\
\hline 3 & 8 & $8 \%$ \\
\hline 4 & 53 & $56 \%$ \\
\hline 5 & 33 & $35 \%$ \\
\hline Total & 95 & $100 \%$ \\
\hline
\end{tabular}

Fuente: Impacto de la estrategia en gestión humana sobre la cultura organizacional y la afectación sobre el medioambiente en las empresas del sector floricultor de la Sabana de Bogotá

De acuerdo con la respuesta anterior se deduce que los líderes de las diferentes áreas en la empresa estudiada han logrado un buen nivel de confianza con los trabajadores. Uno de los grandes problemas organizacionales es que sus trabajadores asuman el error, pues la forma en que se interpreta es como la barrera para desarrollo correcto del desempeño. Es ingenuo pensar que en la ejecución de una tarea la persona no pueda preguntar para evitar cometer un error, y lo que es peor que no pueda preguntar a su jefe o superior, por miedo a un regaño o ser visto como alguien incompetente para el trabajo.

De acuerdo con López (2010) una organización inscrita en la cultura del error se defiende levantando barreras de comunicación, reduciendo su capacidad creativa y el compromiso con los objetivos. Además, los contenidos de la personalidad de los trabajadores actuarán de manera inconsciente, generando desmotivación y desconfianza. De allí entonces que los seres humanos busquen mecanismos de defensa como individualismo competitivo, autoexigencia, manipulación y arrogancia entre otros. Cualidades nada favorables para trabajar en equipo, y lo que es peor un ambiente cargado de expectativas erróneas que solo tratan de ocultar las fallas cometidas, sin lograr solucionarlas ni aprender de ellas.

La pregunta en toma decisiones fue la siguiente:

\section{Figura 6}

La facilidad para participar en la toma de decisiones de su área de trabajo es:

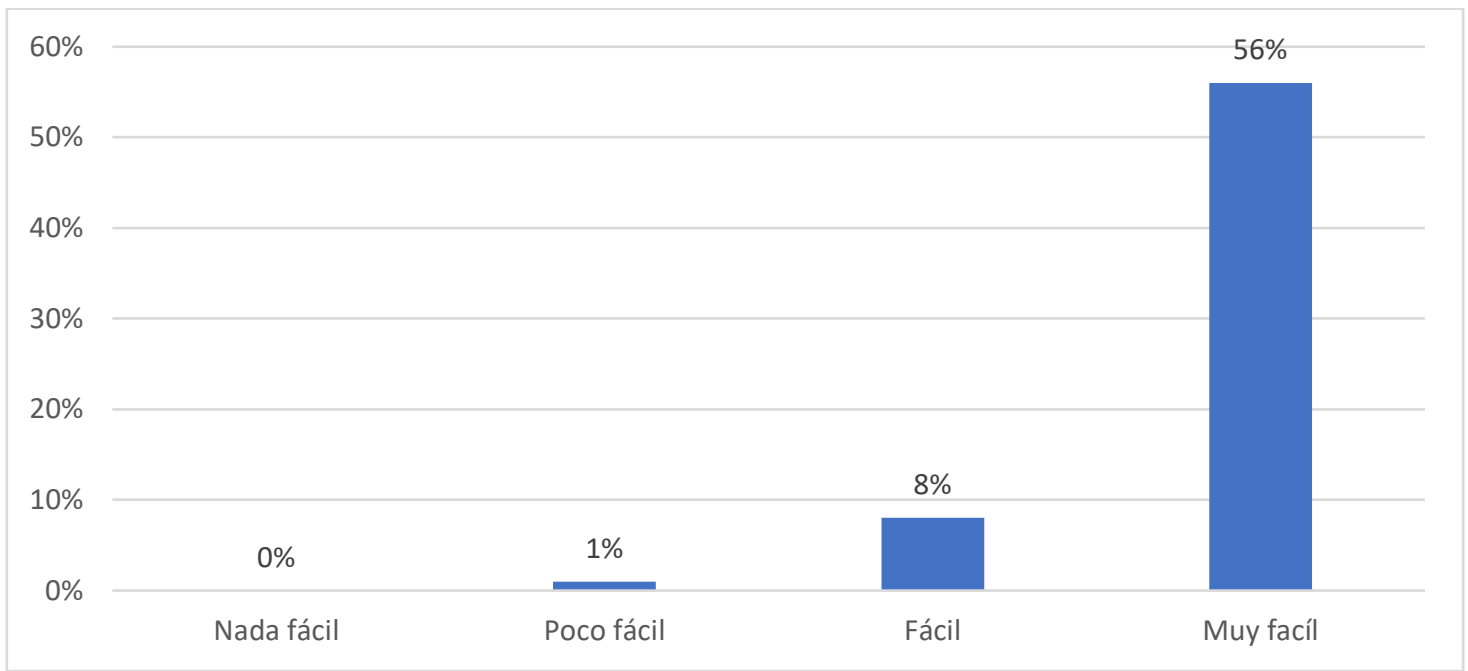




\section{Tabla 6}

La facilidad para participar en la toma de decisiones de su área de trabajo es:

\begin{tabular}{|l|c|c|}
\hline \multicolumn{1}{|c|}{ Selección de pregunta } & Selecciones & \% todas las repuestas de preguntas \\
\hline Nada fácil & 11 & $12 \%$ \\
\hline Poco fácil & 17 & $18 \%$ \\
\hline Fácil & 52 & $55 \%$ \\
\hline Muy fácil & 15 & $16 \%$ \\
\hline Total & 95 & $100 \%$ \\
\hline
\end{tabular}

Fuente: Impacto de la estrategia en gestión humana sobre la cultura organizacional y la afectación sobre el medioambiente en las empresas del sector floricultor de la Sabana de Bogotá

El proceso de toma de decisiones implica una actitud abierta y dispuesta a la escucha de diferentes posiciones y formas de pensar, creando espacios de diálogo encaminados a resolver dificultades y a crear nuevas formas de actuar. Esta capacidad de liderazgo estaría intrínsecamente relacionada con la relación la interacción interpersonal y las alianzas sociales.

Para López (2010) se requiere un nivel de conciencia, que él lo llama el "darse cuenta" en términos de lo que la situación demanda, en términos de tarea y de relación. Esto es fundamental para lograr tomar decisiones en ambientes de adaptaciones rápidas como lo ha sido la pandemia de 2020. Este darse cuenta habla del grado de eficacia de la actividad llevada a cabo por los directivos, supervisores y operarios de la empresa estudiada en el contexto de la cultura endógena y los diferentes agentes de control gubernamentales cultura exógena que exigían lineamientos comportamentales de cuidado y seguridad en el trabajo. Todo esto fue interiorizado junto con los valores corporativos para lograr superar la crisis de entregar el producto a tiempo a los clientes al otro lado del mundo, pese a los inconvenientes de cierre de vías terrestres y aéreas.

Tomar decisiones es un proceso cognitivo y emocional que, con práctica intensa, incrementa la efectividad en la respuesta y optimiza la capacidad de entendimiento y compromiso del líder y de su equipo de trabajo. Todo esto encaminado a mejorar la eficacia, las relaciones interpersonales, bajo la mirada de personas más responsables de su actuar, pensar, sentir y decir, en un proceso de aprendizaje permanente y colaborativo para ambientes de trabajo más agradables y productivos.

\section{Sector Floricultor de la Sabana de Bogotá y su relación con el medioambiente}

Las empresas como entes independientes de sus socios, se consideran sistemas abiertos, por lo cual se interrelacionan de diversas maneras con su entorno físico, natural y ambiental. Al hablar de entorno físico se hace referencia a la ubicación geográfica o la región donde se encuentra inmersa la empresa, lo cual la obliga a compartir con otras organizaciones aspectos económicos, sociales, culturales, tecnológicos, políticos, jurídicos y como ya se dijo ambientales.

Para Gómez Jenifer (2013) cabe señalar que, pese a las variadas conferencias realizadas en torno a lo ambiental, sólo hasta la década de 1990 se tornó de suma relevancia la gestión ambiental empresarial y como parte de las acciones para alcanzar el Desarrollo Sustentable (DS) se habló de sistemas de gestión ambiental (SGA). De allí aparecen las normas ISO 14000, en las cuales se aborda el tema de la gestión ambiental en las organizaciones.

Ahora bien, el DS promovido en las distintas cumbres, no ha buscado limitar el crecimiento económico y la explotación de la naturaleza, por el contrario, el objetivo ha sido 
garantizar la sostenibilidad del desarrollo en términos económicos, llevando la explotación de los recursos naturales a niveles "prudentes", ya que bajo el DS el ambiente es visto como un apéndice, un recurso a ser gestionado para alcanzar no solamente el sostenimiento ambiental, sino el sostenimiento del crecimiento económico. De manera que, acompañar el concepto desarrollo del adjetivo sostenible, "agregándole" así preocupaciones ecológicas, se ha realizado en la medida que no atenta contra los intereses de los agentes económicos, y en tanto que provee las condiciones necesarias para que se siga produciendo la acumulación y el desarrollo económicos de las regiones más poderosas (Latouche, 2007).

Las exigencias para conservar, mitigar y restaurar el medioambiente, han venido creciendo de manera significativa durante los últimos años, lo cual ha originado que las empresas del sector floricultor, estén invirtiendo grandes sumas de dinero en cumplir con la normatividad ambiental nacional y territorial. No obstante, dichas inversiones fueron manejadas por ellas, durante mucho tiempo, como costos que al final terminan teniendo un impacto sobre la competitividad empresarial, en el transcurso de la década de 1990 se empezó a concebir la integración de las cuestiones ambientales a la organización como algo positivo en la medida que la gestión ambiental empresarial dejó de concebirse como un obstáculo a la búsqueda de ganancia y crecimiento en términos económicos, pasando a convertirse en uno de sus componentes principales de la estructura de los gastos a una parte de las cuentas denominadas como inversiones, de igual manera, dicha gestión ambiental representa reducciones de gastos por el ahorro generado en materiales y energías, y se convertía en un factor diferenciador que fortalece la competitividad.

De tal modo, el compromiso con la sustentabilidad por parte de las organizaciones no ha significado únicamente un mejor uso de los recursos naturales y la protección del ambiente, sino que también ha incluido la búsqueda de continuidad de la empresa a través del tiempo, mejoras en los logros financieros y como se dijo, en la competitividad organizacional (Boiral, 2005). En la región Andina Colombiana, específicamente en la Sabana de Bogotá y Cundinamarca, se concentra la mayor cantidad de industrias dedicadas a la actividad de producción de flores. En el 2016, la producción de flores se encontraba distribuida de la siguiente manera: el 72\% en la región de Cundinamarca, el $27 \%$ en Antioquia y el $1 \%$ restante otras regiones (Asocolflores, 2018).

En el estudio, objeto del presente documento se quiso conocer si los funcionarios que laboran en las empresas del sector floricultor de la Sabana de Bogotá conocen qué es y cómo se define el medio ambiente y con satisfacción se encontró que a la pregunta:

\section{Figura 7}

¿Con cuál de las siguientes definiciones sobre medioambiente se identifica más?, el 59\% conocen bien de qué se trata, estos son los resultados:

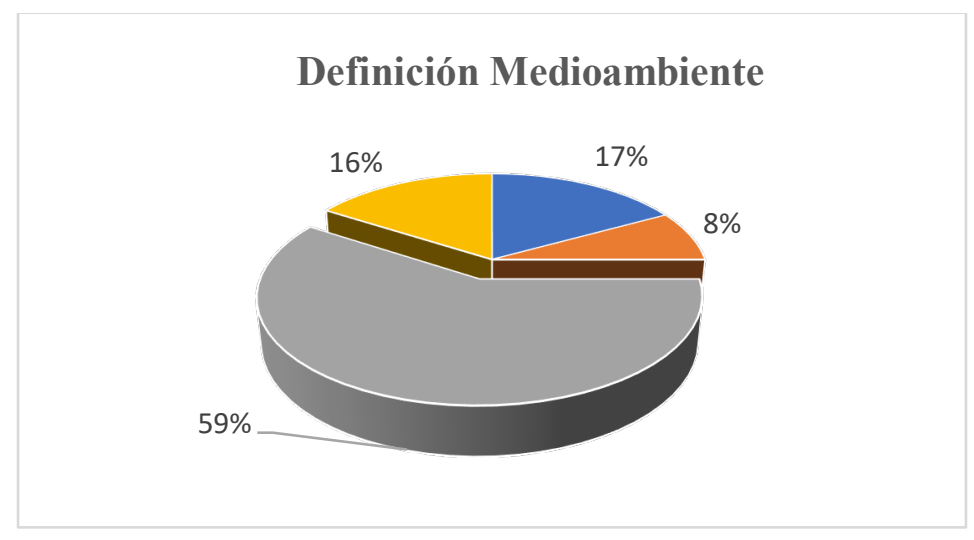


Tabla 7

¿Con cuál de las siguientes definiciones sobre medioambiente se identifica más?, el 59\% conocen bien de qué se trata, estos son los resultados:

\begin{tabular}{|l|c|c|}
\hline \multicolumn{1}{|c|}{ Selección de pregunta } & Selecciones & $\begin{array}{c}\text { \% todas las repuestas de } \\
\text { preguntas }\end{array}$ \\
\hline $\begin{array}{l}\text { Al hablar de medioambiente se hace referencia a la mitad de los seres } \\
\text { vivos que hacen parte del planeta tierra }\end{array}$ & 17 & $17 \%$ \\
\hline $\begin{array}{l}\text { Al hablar de medioambiente se hace referencia al estado anímico que } \\
\text { tiene una persona en un momento determinado }\end{array}$ & 59 & $8 \%$ \\
\hline $\begin{array}{l}\text { Al hablar de medioambiente se hace referencia al conjunto de } \\
\text { circunstancias o factores físicos y biológicos que rodean a los seres } \\
\text { vivos e influyen en su desarrollo y comportamiento }\end{array}$ & 16 & $59 \%$ \\
\hline $\begin{array}{l}\text { Al hablar de medioambiente se hace referencia a los elementos que } \\
\text { conforman el planeta tierra, exceptuando al ser humano }\end{array}$ & $16 \%$ \\
\hline
\end{tabular}

Fuente: Impacto de la estrategia en gestión humana sobre la cultura organizacional y la afectación sobre el medioambiente en las empresas del sector floricultor de la Sabana de Bogotá

\section{Impactos ambientales del proceso productivo que origina el sector floricultor}

La contaminación es un aspecto relevante para destacar del proceso productivo del sector floricultor, empecemos con una corta definición de lo que significa la contaminación ambiental, la cual se puede definir como la presencia de agentes físicos, químicos, o biológicos en el ambiente y los recursos naturales, los que pueden tener efectos nocivos sobre la seguridad y salud de los seres vivos. La contaminación inicia su mayor impacto a partir de la Revolución Industrial, originada en la explotación y sobre explotación de minerales y combustibles fósiles.

Los impactos que el sector floricultor produce sobre el medioambiente, es de diversa índole y por múltiples causas. El presente documento presenta los resultados arrojados por la investigación denominada "Impacto de la estrategia en gestión humana sobre la cultura organizacional y la afectación sobre el medioambiente en las empresas del sector floricultor de la Sabana de Bogotá", realizada por los docentes de la Universidad de La Salle, Esperanza Díaz Vargas y Gerardo Mogollón Pita, quienes aplicaron una encuesta a 100 funcionarios que laboran en diversas empresas floricultoras de la Sabana de Bogotá.

Impactos negativos del sector floricultor de la Sabana de Bogotá sobre el medioambiente.

Para la entidad Ecología Verde el impacto negativo sobre el medio ambiente hace referencia a aquellas alteraciones que perjudican tanto el medio natural como la salud humana. Las principales consecuencias son la contaminación del planeta (tierra, agua, y aire), la pérdida de biodiversidad y el incremento de enfermedades y problemas de salud.

La encuesta objeto del presente escrito, muestra que a la pregunta: mencione un impacto (ya sea positivo o negativo) que sobre el medioambiente o los recursos naturales origina el proceso productivo de la empresa dónde trabaja.

De los encuestados el $41 \%$ señalan, dentro los impactos negativos que el proceso productivo del sector floricultor de la Sabana de Bogotá, el principal problema es la contaminación por esparcimiento o vertimiento de residuos químicos, originada por el uso de fertilizantes, agroquímicos, pesticidas, fungicidas y demás elementos usados en los cultivos y que al fumigar se escapan y terminan en la atmosfera, el suelo y los afluentes hídricos. 


\section{Figura 8}

Impactos Negativos sobre el Medioambiente

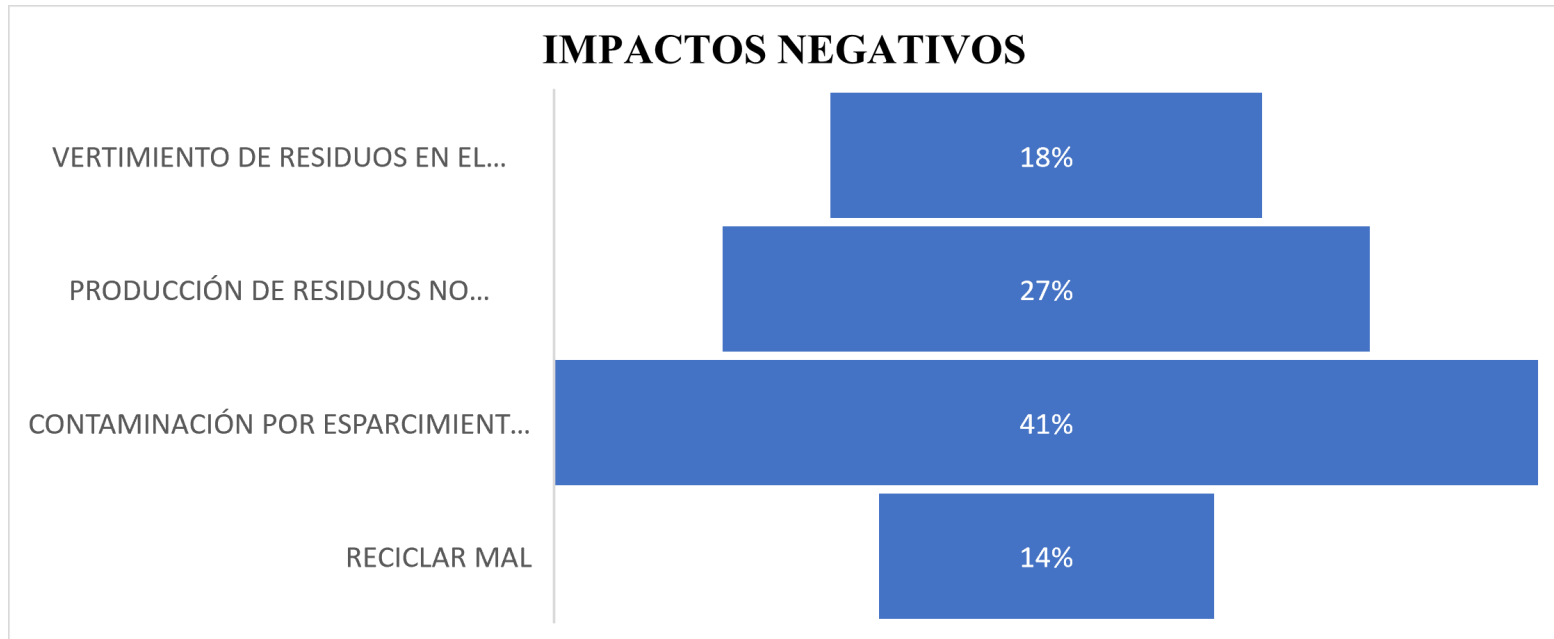

Tabla 8

Impactos Negativos sobre el Medioambiente

\begin{tabular}{|l|c|}
\hline \multicolumn{1}{|c|}{ IMPACTOS NEGATIVOS } & \% todas las repuestas de preguntas \\
\hline VERTIMIENTO DE RESIDUOS EN EL AGUA & $18 \%$ \\
\hline PRODUCCIÓN DE RESIDUOS NO DEGRADABLES & $27 \%$ \\
\hline CONTAMINACIÓN POR ESPARCIMIENTO QUIMICO & $41 \%$ \\
\hline RECICLAR MAL & $14 \%$ \\
\hline TOTAL & $100 \%$ \\
\hline
\end{tabular}

Fuente: Impacto de la estrategia en gestión humana sobre la cultura organizacional y la afectación sobre el medioambiente en las empresas del sector floricultor de la Sabana de Bogotá

Se resalta que en Colombia los productos químicos, vendidos en el país, deben cumplir con lo estipulado en el documento del Sistema globalmente armonizado de clasificación y etiquetado de productos químicos - SGA.

Según el SGA, los peligros originados por los productos químicos deben cumplir con los siguientes preceptos:

a) La identificación de los datos pertinentes a los peligros de una sustancia química o una mezcla de sustancias.

b) La revisión de los datos recopilados para comprobar los peligros asociados con esa sustancia química o mezcla de sustancias.

c) La decisión sobre si la sustancia química o la mezcla se clasificará como sustancia o mezcla peligrosa, y su grado de peligrosidad, contrastando la información disponible con los criterios definidos para la clasificación de peligros.

Además de los peligros físicos que representan los químicos, se contemplan peligros para la salud y para el medioambiente, en este último ítem se resaltan los peligros para el ambiente acuático y los peligros para la capa de ozono.

Entre los productos a los que les aplica el SGA se encuentran los plaguicidas químicos de uso agrícola: el uso de plaguicidas está muy generalizado en todo el mundo, a pesar de que 
representan peligros para quienes los producen o los usan, así como para el ambiente en el cual se utilizan. Los agricultores y los trabajadores del campo corren riesgo de exposición por el uso de diferentes productos químicos agrícolas, principalmente los plaguicidas. La Organización Mundial de la Salud - OMS, estima que el número total de casos de intoxicación por plaguicidas en el sector agrícola oscila entre los 2 y los 5 millones al año, de los cuales 40.000 son fatales (hoyos, 2020, pág.18).

En un segundo lugar, con un $27 \%$, se encuentra la producción de residuos no degradables como son elementos plásticos, mallas, cauchos, etc., los cuales al no ser biodegradables originan una acumulación de desechos que terminan contaminando.

Con menor porcentaje, pero igualmente preocupante está el vertimiento de residuos en el agua $18 \%$ y el mal reciclaje en un $14 \%$.

Los funcionarios encuestados también resaltan impactos positivos sobre el medioambiente, originados por las empresas del sector floricultor de la Sabana de Bogotá, entre los que se resaltan:

\section{Figura 9}

Impactos Positivos sobre el Medioambiente

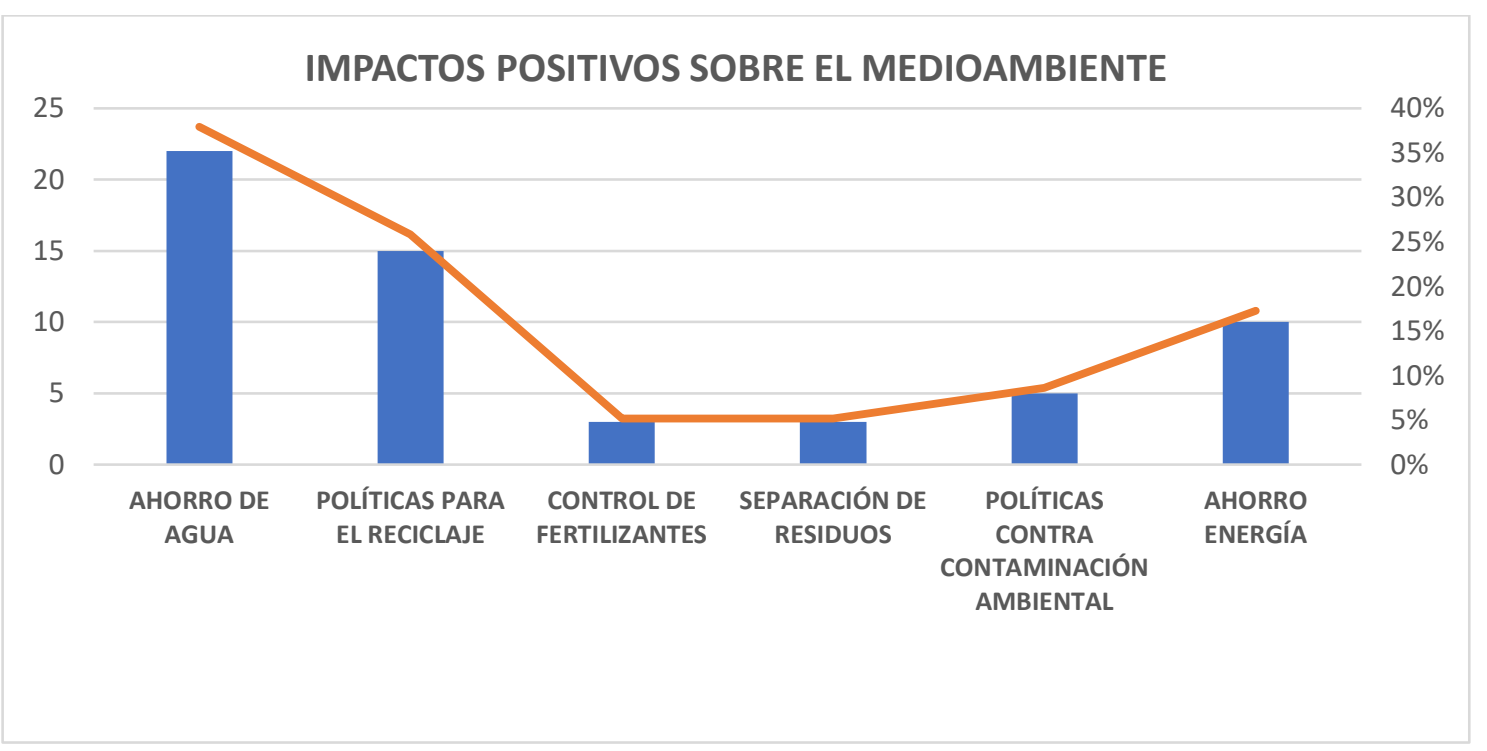

Tabla 9

Impactos Positivos sobre el Medioambiente

\begin{tabular}{|l|c|c|}
\hline \multicolumn{1}{|c|}{ IMPACTOS POSITIVOS } & Selecciones & \% todas las repuestas de preguntas \\
\hline AHORRO DE AGUA & 22 & $38 \%$ \\
\hline POLÍTICAS PARA EL RECICLAJE & 15 & $26 \%$ \\
\hline CONTROL DE FERTILIZANTES & 3 & $5 \%$ \\
\hline SEPARACIÓN DE RESIDUOS & 3 & $5 \%$ \\
\hline $\begin{array}{l}\text { POLÍTICAS CONTRA CONTAMINACIÓN } \\
\text { AMBIENTAL }\end{array}$ & 5 & $9 \%$ \\
\hline AHORRO ENERGÍA & 10 & $17 \%$ \\
\hline
\end{tabular}

Fuente: Impacto de la estrategia en gestión humana sobre la cultura organizacional y la afectación sobre el medioambiente en las empresas del sector floricultor de la Sabana de Bogotá 
En primer lugar, con un 38\% se resalta el ahorro de agua, pues las empresas cuentan con sistemas de reciclaje, utilización y reutilización de aguas lluvia, las cuales son recolectadas y depositadas en lo que ellos llaman embalses. El 26\% indica que las empresas estudiadas cuentan con políticas claras de reciclaje de productos orgánicos, residuos plásticos, papel, cartón, vidrío, entre otros. Lo anterior va unido a políticas de ahorro de energía (17\%), políticas organizacionales contra la contaminación $(9 \%)$, separación de residuos $(5 \%)$ y control de fertilizantes en igual medida (5\%).

Las empresas del sector floricultor de la Sabana de Bogotá, cuentan con plantas de tratamiento de aguas residuales con las cuales se busca garantizar la calidad del líquido al igual que cumplir con las normas que desde 1978 se vienen expidiendo y buscan minimizar los efectos adversos sobre la salud de las personas y sobre el medioambiente.

\section{Sistema de Gestión Ambiental (SGA)}

La norma NTC ISO-14001 señala El sistema de Gestión Ambiental (SGA) es la parte de la gestión que emplea una organización para desarrollar e implementar la política ambiental, basada en la prevención de la contaminación y la mejora continua del comportamiento ambiental, este SGA está construido bajo el modelo o ciclo "planificar, hacer, comprobar y actuar".

- Planificar, incluyendo los aspectos ambientales, estableciendo los objetivos y las metas a seguir.

- Hacer, implementando la formación y los controles operacionales necesarios.

- Verificar, obteniendo los resultados del seguimiento y corrigiendo las desviaciones observadas.

- Actuar, revisando el progreso obtenido y efectuando los cambios necesarios para la mejora del sistema.

Sobre el particular también se les consultó a los funcionarios de las empresas del sector floricultor de la Sabana de Bogotá, de la siguiente manera:

El sistema de gestión ambiental (SGA) de una empresa, es un instrumento de carácter voluntario establecido para alcanzar un alto nivel de protección del medioambiente en el marco del "desarrollo sostenible".

\section{Figura 10}

¿conoce usted si la empresa donde labora cuenta con un sistema de gestión ambiental $(S G A)$ ?

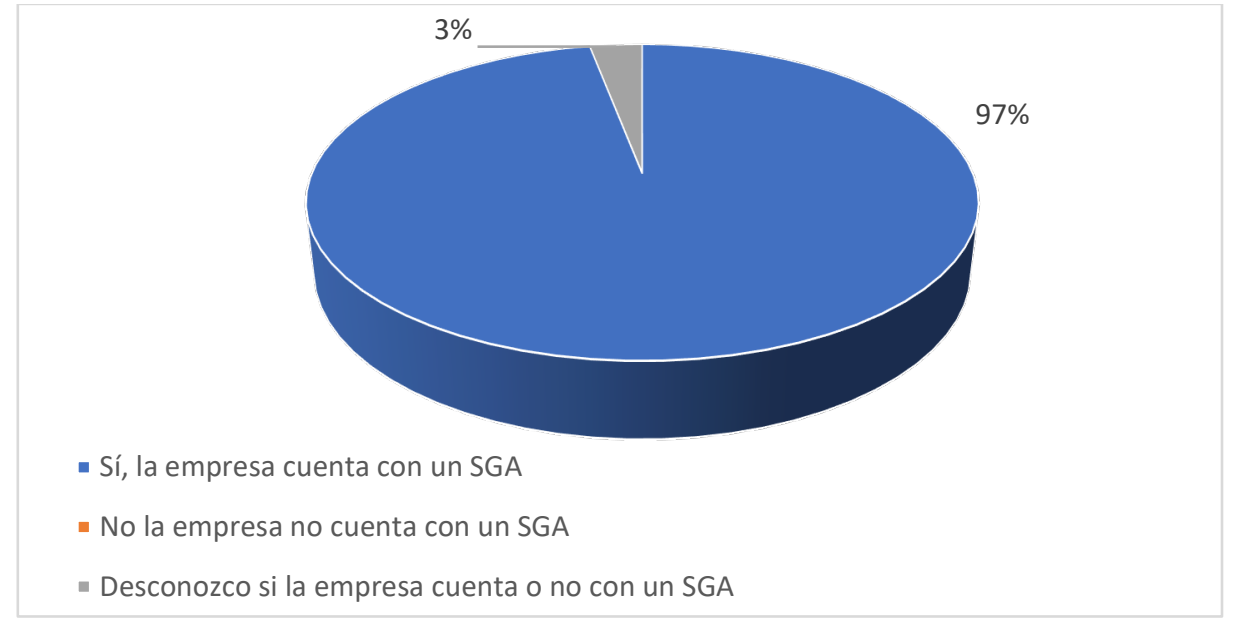


Tabla 10

¿conoce usted si la empresa donde labora cuenta con un sistema de gestión ambiental $(S G A)$ ?

\begin{tabular}{|l|c|c|}
\hline \multicolumn{1}{|c|}{ Selección de pregunta } & Selecciones & \% todas las repuestas de preguntas \\
\hline Sí, la empresa cuenta con un SGA & 97 & $97 \%$ \\
\hline No la empresa no cuenta con un SGA & 0 & $0 \%$ \\
\hline Desconozco si la empresa cuenta o no con un SGA & 3 & $3 \%$ \\
\hline Total & 100 & $100 \%$ \\
\hline
\end{tabular}

Fuente: Impacto de la estrategia en gestión humana sobre la cultura organizacional y la afectación sobre el medioambiente en las empresas del sector floricultor de la Sabana de Bogotá

Las respuestas son esperanzadoras, pues el $97 \%$ de las personas manifiestan que efectivamente las empresas sí cuentan con un sistema de gestión ambiental, ninguno niega que no lo tuviera; solo el 3\% manifiesta desconocer que la empresa lo tiene o no, así las cosas, puede que de manera tácita no se hable de SGA, pero toda empresa cuenta con políticas encaminadas a mitigar el impacto que el proceso productivo origina sobre el medioambiente y los recursos naturales.

Como se mencionó anteriormente, en Colombia existe una amplia y diversa normatividad encaminada a la mitigación y protección de los recursos naturales y del medio ambiente, a continuación, se hace una breve reseña de estas:

\section{Tabla 11}

\section{Normatividad Colombiana para el tratamiento de aguas residuales}

\begin{tabular}{|l|l|}
\hline \multicolumn{1}{|c|}{ NORMA } & \multicolumn{1}{c|}{ ALCANCE } \\
\hline Decreto 1541 de 1978 & Reglamenta los usos de las aguas no marítimas. \\
\hline Decreto 1594 de 1984 & Reglamenta sobre Usos del agua y residuos líquidos \\
\hline Ley 373 de 1997 & Programa para el uso eficiente y ahorro de agua \\
\hline Decreto 3100 de 2003 & $\begin{array}{l}\text { Se reglamentan las tasas retributivas por la utilización directa del agua como } \\
\text { receptor de los vertimientos puntuales }\end{array}$ \\
\hline Decreto 1575 de 2007 & $\begin{array}{l}\text { Por el cual se establece el Sistema para la Protección y control de la Calidad } \\
\text { Agua para consumo humano y sus Resoluciones reglamentarias. Derogan el } \\
\text { Decreto 475 de 1998 }\end{array}$ \\
\hline Decreto 1324 de 2007 & $\begin{array}{l}\text { Por el cual se crea el Registro de Usuarios del Recurso Hídrico y se dictan otras } \\
\text { disposiciones }\end{array}$ \\
\hline Decreto 1323 de 2007 & Por el cual se crea el Sistema de Información del Recurso Hídrico \\
\hline Decreto 3930 de 2010 & $\begin{array}{l}\text { Establece las disposiciones relacionadas con los usos del recurso hídrico, el } \\
\text { Ordenamiento del Recurso Hídrico y los vertimientos al recurso hídrico, al suelo } \\
\text { y a los alcantarillados. }\end{array}$ \\
\hline Decreto 1076 de 2015 & $\begin{array}{l}\text { Promueve el Reúso de las Aguas Residuales a través de los Planes de } \\
\text { Reconversión a Tecnologías Limpias en Gestión de Vertimientos }\end{array}$ \\
\hline Decreto 050 de 2018 & $\begin{array}{l}\text { "Por el cual se modifica parcialmente el Decreto 1076 de 2015, Decreto Único } \\
\text { Reglamentario del Sector Ambiente y Desarrollo Sostenible en relación con los } \\
\text { Consejos Ambientales Regionales de la Microcuencas (CARMAC), el } \\
\text { Ordenamiento del Recurso Hídrico y Vertimientos y se dictan otras disposiciones }\end{array}$ \\
\hline
\end{tabular}

Fuente: Impacto de la estrategia en gestión humana sobre la cultura organizacional y la afectación sobre el medioambiente en las empresas del sector floricultor de la Sabana de Bogotá

Se aclara que las nomas anteriormente señaladas, corresponden a normas de carácter nacional, no obstante, las entidades territoriales también están facultadas y de hecho así lo hacen, de promulgar sus propias normas que le son aplicables a la circunscripción de sus territorios (acuerdos, resoluciones). 
Teniendo en cuenta que la normatividad, bien sea nacional, departamental o municipal, le son de obligatorio cumplimiento a las empresas se les hizo a los funcionarios la siguiente pregunta:

\section{Figura 11}

$¿$ ¿Conoce usted la normatividad de indole medioambiental (Leyes, Decretos, Acuerdos, Resoluciones, Etc.) que le son aplicables a la empresa donde labora?

No, Desconozco completamente la normatividad ambiental

Sí, Conozco algunas de las normas

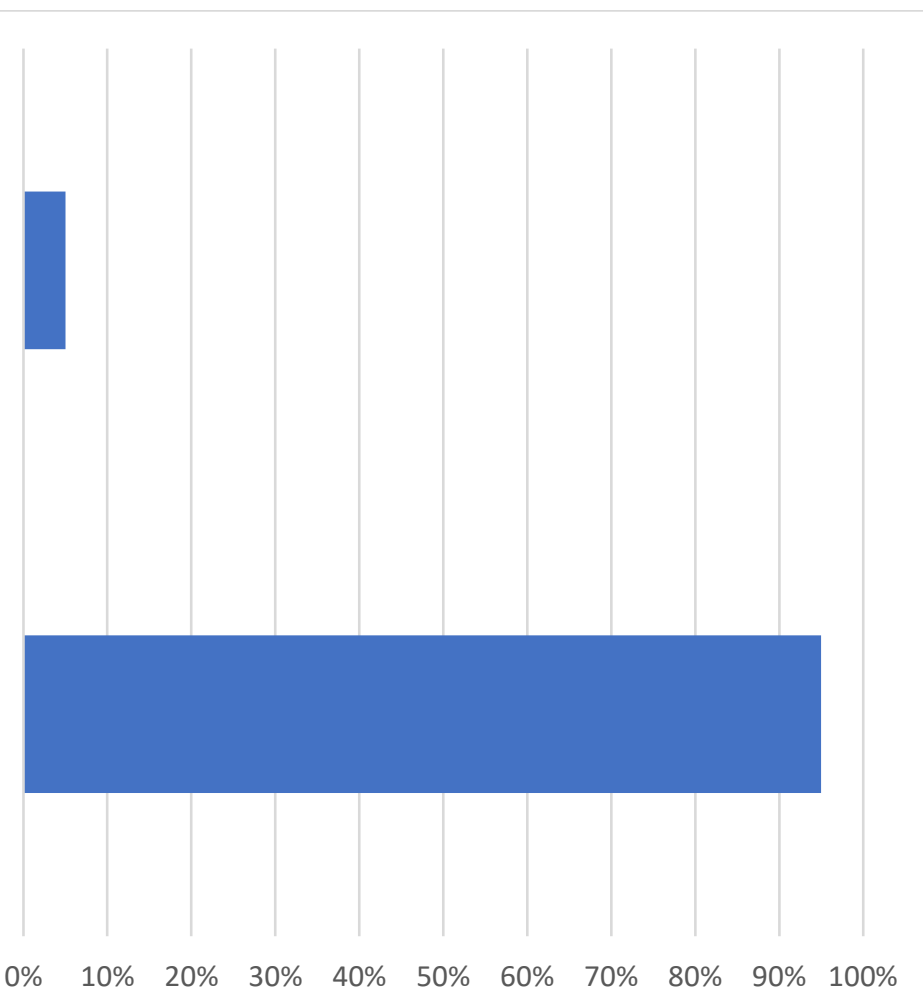

Tabla 12

¿Conoce usted la normatividad de indole medioambiental (Leyes, Decretos, Acuerdos, Resoluciones, Etc.) que le son aplicables a la empresa donde labora?

\begin{tabular}{|l|c|c|}
\hline \multicolumn{1}{|c|}{ Selección de pregunta } & Selecciones & \% todas las repuestas de preguntas \\
\hline Sí, Conozco algunas de las normas & 95 & $95 \%$ \\
\hline No, Desconozco completamente la normatividad ambiental & 5 & $5 \%$ \\
\hline Total & 100 & $100 \%$ \\
\hline
\end{tabular}

Fuente: Impacto de la estrategia en gestión humana sobre la cultura organizacional y la afectación sobre el medioambiente en las empresas del sector floricultor de la Sabana de Bogotá

En las reuniones que sostuvieron los investigadores del presente proyecto con la parte administrativa de las empresas objeto de estudio se puedo comprobar que dichas empresas cumplen con la normatividad vigente y que realizan constante capacitación a sus trabajadores, es por ello por lo que a la anterior pregunta la respuesta "sí, conozco algunas de las normas" sumó el 95\% y tan solo un 5\% aduce no conocer completamente la normatividad ambiental; lo anterior se corrobora con la siguiente pregunta: 
Figura 12

¿Usted ha recibido capacitación sobre el tema medioambiental en la empresa donde labora?

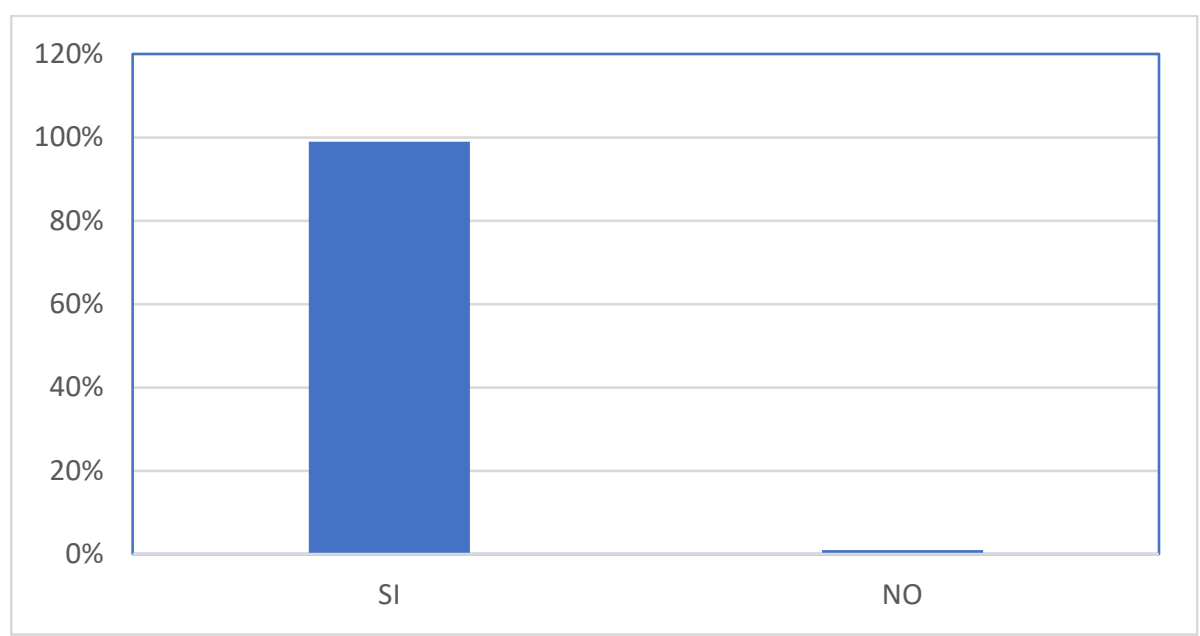

Tabla 13

¿Usted ha recibido capacitación sobre el tema medioambiental en la empresa donde labora?

\begin{tabular}{|c|c|}
\hline Selección de pregunta & \% todas las repuestas de preguntas \\
\hline SI & $99 \%$ \\
\hline NO & $1 \%$ \\
\hline Total & $100 \%$ \\
\hline
\end{tabular}

Fuente: Impacto de la estrategia en gestión humana sobre la cultura organizacional y la afectación sobre el medioambiente en las empresas del sector floricultor de la Sabana de Bogotá

El 99\% de los encuestados señalan que sí los han capacitado en temas de protección, mitigación y conservación del medioambiente, tan solo el 1\% manifestó que no, se vuelve a corroborar que esto se debe a una política empresarial y del sector floricultor.

Por el conocimiento que los trabajadores tienen en asuntos medioambientales es importante conocer cuál es la percepción que ellos tienen sobre el efecto que el proceso productivo de sus empresas tiene sobre el medioambiente y los recursos naturales, estas son las respuestas a la siguiente pregunta:

\section{Figura 13}

Considera usted que el efecto sobre el medioambiente y los recursos naturales que origina el proceso productivo de la empresa donde labora es:

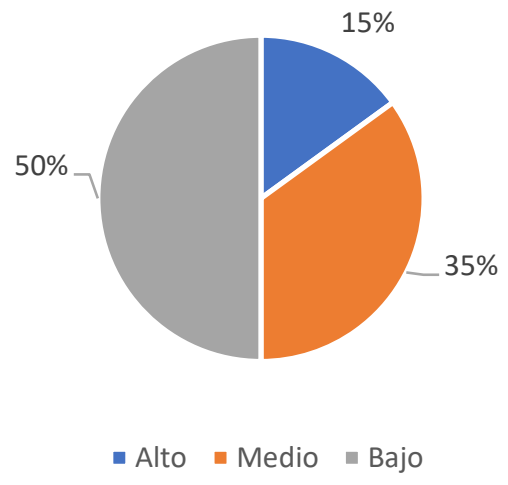




\section{Tabla 14}

Considera usted que el efecto sobre el medioambiente y los recursos naturales que origina el proceso productivo de la empresa donde labora es:

\begin{tabular}{|c|c|c|}
\hline Selección de pregunta & Selecciones & \% todas las repuestas de preguntas \\
\hline Alto & 15 & $15 \%$ \\
\hline Medio & 35 & $35 \%$ \\
\hline Bajo & 50 & $50 \%$ \\
\hline Total & 100 & $100 \%$ \\
\hline
\end{tabular}

Fuente: Impacto de la estrategia en gestión humana sobre la cultura organizacional y la afectación sobre el medio ambiente en las empresas del sector floricultor de la Sabana de Bogotá

Las políticas que aplican las empresas llevan a que sus empleados tengan una percepción de que el efecto del proceso productivo de sus empresas sobre el medioambiente es bajo, pues así lo respondió el 50\% de los encuestados, el 34\% dice que el efecto es medio y el $15 \%$ dice que es alto.

Por último, los investigadores consideran que quienes mejor conocen los efectos que el proceso productivo de cualquier organización, son sus trabajadores y que en gran medida si a ellos se les escucha, se les atienden sus recomendaciones, y siempre y cuando exista una cultura organizacional que así lo permita, la más beneficiada sería la empresa, por eso a los encuestados se les hizo la siguiente pregunta:

\section{Figura 14}

¿Usted ha realizado, sugerido o recomendado a su empresa, alguna actividad o procedimiento que pueda ayudar a mitigar el impacto que el proceso productivo origine sobre el medioambiente y los recursos naturales?

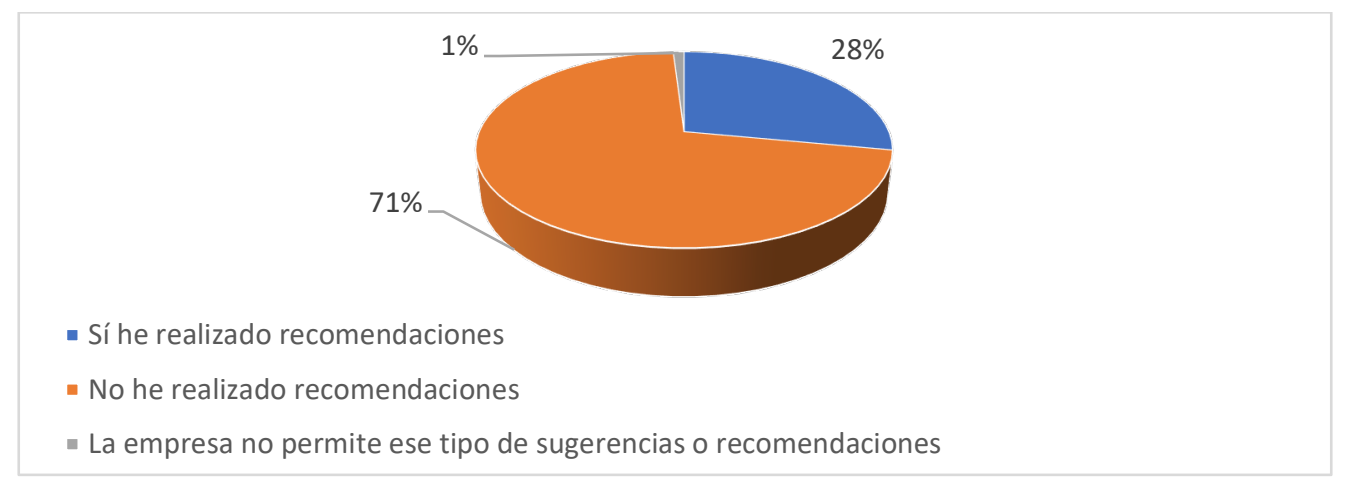

\section{Tabla 15}

¿Usted ha realizado, sugerido o recomendado a su empresa, alguna actividad o procedimiento que pueda ayudar a mitigar el impacto que el proceso productivo origine sobre el medioambiente y los recursos naturales?

\begin{tabular}{|l|c|c|}
\hline \multicolumn{1}{|c|}{ Selección de pregunta } & Selecciones & $\begin{array}{c}\text { \% todas las repuestas de } \\
\text { preguntas }\end{array}$ \\
\hline Sí, he realizado recomendaciones & 28 & $28 \%$ \\
\hline No he realizado recomendaciones & 71 & $71 \%$ \\
\hline La empresa no permite ese tipo de sugerencias o recomendaciones & 1 & $1 \%$ \\
\hline Total & 100 & $100 \%$ \\
\hline
\end{tabular}

Fuente: Impacto de la estrategia en gestión humana sobre la cultura organizacional y la afectación sobre el medio ambiente en las empresas del sector floricultor de la Sabana de Bogotá 
El 71\% de los encuestados respondieron que no han realizado recomendaciones a sus empresas para ayudar a mitigar los impactos negativos que el proceso productivo origina sobre el medioambiente, puede ser porque los trabajadores consideran que no es necesario puesto que las políticas organizacionales son adecuadas. El 28\% responde que sí ha realizado recomendaciones y tan solo el $1 \%$ contesta que la empresa no permite ese tipo de recomendaciones.

\section{Conclusiones}

El estudio realizado a las empresas del sector floricultor de La Sabana de Bogotá permite concluir que ellas cuentan con un Sistema de Gestión Ambiental encaminado a cumplir las normas de índole nacional, departamental y municipal. Estas normas tienen como fin mitigar el impacto negativo que su proceso productivo origina sobre el medioambiente y los recursos naturales que el SGA comulga con las políticas que cada organización tiene establecidas según su gobierno corporativo y que, entre otras, están encaminadas a una permanente capacitación de sus trabajadores.

El SGA y las políticas implementadas por las empresas coadyuvan a que el impacto originado sobre el medioambiente permita que sea lo menos perjudicial, encontrándose aún efectos originados por el uso de productos con componentes químicos, utilización de elementos no biodegradables que pueden ser mal reciclados o que no se tenga claro el proceso de aprovechamiento de ellos. No obstante, también se encuentran políticas claras en materia de protección y mitigación resaltando el ahorro de agua y energía, políticas para el reciclaje y cada vez utilizar menos fertilizantes, plaguicidas y pesticidas que contengan elementos químicos.

La cultura organizacional interiorizada en cada uno de los miembros de la organización floricultora propicia un ambiente para que los trabajadores planteen soluciones a los problemas de su área. Aportando de esta manera un ambiente adecuado para la toma de conciencia, en las decisiones generando diálogo y promoviendo las buenas prácticas de relacionamiento en el sitio de trabajo. Lo que permite mejorar notablemente procesos de motivación y por ende de productividad, a esto se le conoce como una cultura de solución y no de miedo y sanción.

Se puede afirmar que el camino más seguro entre la estrategia de gestión humana y las condiciones esperadas de bienestar y prosperidad en este tipo de empresas del sector floricultor, es aquel que introduce mediaciones culturales entre los recursos naturales, el talento humano, el capital y el producto. De esta manera se crea conciencia en cada líder multiplicando los significados, sentimientos, lógicas y valores en torno al trabajo como condición humana que permita generar y producir satisfacción y bienestar a través de lo que se hace con responsabilidad social y ambiental.

\section{Referencias}

Ávila, R. M. (2018). La floricultura y su dimensión humana. (consultado el 15 de agosto de 2021 disponible en internet: https://www.metroflorcolombia.com/la-floricultura-y-su-dimension-humana/

Calderón, M., Orjuela J.A. (2005). Competitividad en la agroindustria láctea.

Casado, E. L. (1999). Organizaciones triunfadoras. Guía breve de análisis transaccional aplicado a las organizaciones, $1^{\text {a }}$ edición, Gestión 2000, Barcelona-España.

Conesa, F.V. (1997). Auditorías Medioambientales - Guía Metodológica. Ediciones Mundiprensa. 
Curso de auditorías medioambientales. (2004). Buenos Aires. Disponible www.cepis.org.pe/.

Departamento Administrativo Nacional de Estadística - DANE. (2010). Informe De Resultados: Censo de Fincas Productoras de Flores En 28 municipios de la Sabana de Bogotá yCundinamarca2009.Disponible https://www.dane.gov.co/files/investigaciones/boletines/flores/Informe_resultados_2009.pdf

Díaz. E. (2017). Desarrollo de competencias gerenciales en los directivos y supervisores de una empresa floricultora de la Sabana de Bogotá. Libro digital Educación digital y gestión del talento humano en Iberoamérica pp.495-513. Corporación Centro Internacional de Marketing Territorial para la Educación y el Desarrollo.

Díaz. E. (2020). Aprendizaje organizacional estrategia infalible de la competitividad empresarial. Libro digital Tecnociencia y Sociedad pp.172-191. Corporación Centro Internacional de Marketing Territorial para la Educación y el Desarrollo.

Eichholz, J.C. (2015) Capacidad Adaptativa, Cómo las organizaciones pueden sobrevivir y desarrollarse en un mundo cambiante. Ediciones de la U. Bogotá-Colombia.

Friedemann, S. (2008). Ensamblar flores y cultivar hogares. Instituto colombiano de antropología e historia. Taller de edición Roca. S.A.

Fondo de las Naciones Unidas para la alimentación, (FAO). (1997) La Agroindustria y el desarrollo económico.

Gama. L., Mogollón. G., Guarnizo, F., Quintana, A., Vergara. L., Aldana, A. (2010) Diseño de un modelo de AA para ser aplicado en el sector de la industria láctea, trabajo de investigación auspiciado por la universidad de La Salle (Sin edición)

García-Astillero, A. (2019). Qué es el impacto ambiental negativo y positivo (en línea) Ecología Verde (consultado el 12 de agosto de 2021 disponible en internet: https:/www.ecologiaverde.com/que-esimpacto-ambiental-negativo-y-positivo-con-ejemplos-

1512.html\#: :text=Los\%20impactos\%20ambientales\%20negativos\%20son, enfermedades\%20y\%20pro blemas\%20de \%20salud.

Gray. R., Bebbing J. Traductor Mantilla S. (2006). Contabilidad y AA. Bogotá: Ecoe Ediciones.

Hoyos, C. Martha C. (2016-2020), Estrategia Nacional para la implementación del Sistema globalmente armonizado de clasificación y etiquetado de productos químicos - SGA - en Colombia.

López, A. (2010). El éxito sostenible a través del error. Editorial Díaz de Santos. España.

Méndez, C. (2006) Transformación cultural en las organizaciones: un modelo para la gestión del cambio. Editor Limusa, Universidad del Rosario. Bogotá-Colombia.

Mogollón, G., Vergara, L. (2007). Diseño de un Estado financiero de propósito especial ambiental para ser aplicado en el sector lácteo. Bogotá, D.C. Trabajo de Investigación, Auspiciado por la Universidad de La Salle (sin edición).

Motta, R. (1993). La ciencia y el arte de ser dirigente. Ediciones Uniandes.Bogotá-Colombia.

Martínez Avella, M. E. (2010). Relaciones entre cultura y desempeño organizacional en una muestra de empresas colombianas: reflexiones sobre la utilización del modelo de Denison. Cuadernos de administración, 23(40).

Maseko, T. B. (2017). Strong vs. Weak Organizational Culture: Assessing the Impaction Employee Motivation. Arabian Journal of Business and Management Review, (7), 1-5.

Ministerio de Agricultura y Desarrollo rural, documento de trabajo No.4., Disponible en: www.minagricultura.gov.co.Organización Internacional para la Estandarización - ISO 19011, Disponible en: http://www.eie.fceia.un 
Rodríguez, R. (1998). Guías para Realizar Auditorías Ambientales, Universidad de las Palmas, Gran Canarias (España).

Robbins, S. P. (1996). Comportamiento organizacional: teoría y práctica, $7^{\mathrm{a}}$ edición. Prentice Hall Hispanoamericana S.A. México.

Rodríguez, D. (2005). Diagnóstico Organizacional. Ediciones Alfaomega. México.

Sao Paulo. S. A. (2009). Agricultura y pesca. Contaminación. Disponible en http://www.juntadeandalucia.es/agriculturaypesca.

Ortiz, S., Rodríguez, J. Universidad de La Salle. Facultad de Ciencias Administrativas y Contables. Administración de Empresas; Language: Spanish; Castilian. http://eds.b.ebscohost.com/eds/results?vid=0\&sid=ecafc89a-a563-4da6-9c52437bf5701f1a\%40sessionmgr 103\&bquery $=$ ortiz $\% 2 B y \% 2 B r o d r i g u e z \% 2 B C u l t u r a \% 2 B o r g a n i z a c i o n a l \%$ 2Bempresa\%2Bxyz\&bdata=JkF1dGhUeXBIPWlwLHVybCx1aWQmbGFuZz1lcyZ0eXBlPTAmc2Vh cmNoTW9kZT1BbmQmc210ZT11ZHMtbG12ZQ\%3d\%3d, dcBase de datos: Ciencia Unisalle

Serna, H. (1994) Planeación y gestión estratégica: teoría y metodología, Legis editores. S.A., Bogotá-Colombia.

Sistema de Gestión Ambiental Bajo Norma NTC ISO-14001 (en línea) Min Comercio Industria y Turismo (consultado el 12 de agosto de 2021) disponible en internet:

https://www.mincit.gov.co/publicaciones/8150/sistema_de_gestion_ambiental_mincit_bajo_la_ntc_iso _14001_2004

Superintendencia de Sociedades, 2020. Informe de Gestión 2020.

https://www.supersociedades.gov.co/nuestra_entidad/Control/Informes\%20Anuales/Informe-Gestion2020.pdf\#search=informe $\% 20$ sector $\% 20$ flores $\% 202020$

Superintendencia de Sociedades, 2017. Informe de Gestión 2017. https://www.supersociedades.gov.co/delegatura_aec/estudios_financieros/Documents/Sectores\%20Eco $\mathrm{n} \% \mathrm{C} 3 \%$ B3micos/EE-Estudio\%20sector\%20Flores-2017\%2009\%2028.pdf

Stewar, G., Manz Ch., Sims, H. (2003). Trabajo en equipo y dinámica de grupos. Editorial Limusa Wiley. México D.F.

Universidad Distrital de Caldas. Disponible en URL: www. Agrocadenas.gov.co/ documentos/ agroindustria/ Agroindustria_lacteos.pdf.

US-EPA. (1995). An introduction to environmental accounting as a business management tool: key concepts and terms. United States Environmental Protection Agency- Office of Prevention and Toxics, Washington D.C.

Vega, L. (2001). Gestión Ambiental Sistémica, Bogotá: Ecoe. http://cursogestionambiental.blogspot.com/, consultado octubre 21 de 2014. 